\title{
Bourneville-Pringle disease (Tuberous Sclerosis Complex - TSC) with bilateral renal angiomyolipoma and an epitheloid monomorf angiomyolipoma (EM- $A M L)$ in a 43-year- old female, a case report
}

Kinga Mate ( $\square$ matekingabrigitta@gmail.com )

Péterfy Sándor Hospital and Traumatology Center https://orcid.org/0000-0001-7791-1759

\section{Fanni Márványkövi}

Péterfy Sándor Hospital and Traumatolgy Center, Budapest, Hungary

\section{László Vrecenár}

Péterfy Sándor Hospital and Traumatology Center, Budapest, Hungary

\section{Tamás Zóber}

Péterfy Sándor Hospital and Traumatology Center, Budapest, Hungary

\section{István Buzogány}

Péterfy Sándor Hospital and Traumatology Center, Budapest, Hungary

\section{Tamás Beöthe}

Péterfy Sándor Hospital and Traumatology Center, Budapest, Hungary

\section{Research Article}

Keywords: Bourneville-Pringle disease, tuberous sclerosis complex (TSC), angiomyolipoma (AML), fatpoor AML, epitheloid monomorf angiomyolipoma (EM-AML), nephrectomy, ablation, embolization, mTOR inhibitor

Posted Date: February 18th, 2022

DOI: https://doi.org/10.21203/rs.3.rs-1093873/v1

License: (c) (i) This work is licensed under a Creative Commons Attribution 4.0 International License. Read Full License 


\section{Abstract}

Background: The Bourneville Pringle disease, also called tuberous sclerosis complex (TSC) is a rare genetic disorder with dominant autosomal inheritance. It is a rare neurocutaneous disorder, which can affect numerous internal organs, for example the kidney(s), the heart, and the lungs. The formation of multiple hamartomas is causing the multiorgan systemic involvement.

Case presentation: A 43-year-old patient presents with tuberous sclerosis, an autosomal dominant inherited neurocutaneous disorder which variably affects different organs, among them the kidneys. During follow-up the abdominal computer tomography (CT) showed bilateral angiolipomatosis (AML) and a fat-poor mass with a different solid aspect on the left side. A fat-poor AML can be a challenge to diagnose. It is vital to exclude malignancy to decide on further management. A CT guided biopsy was performed. The results showed an atypical renal angiomyolipoma, a rare monomorph, epitheloid type. A genetic examination was performed, which showed a mutation of the TSC2 genes.

Conclusions: The Bourneville Pringle disease is a rare genetic, neurocutaneous disease, which can affect multiple organs by the formation of hamartomas, including renal manifestation as AML. In case of radiological findings of a fat poor CT component AML it is essential to keep in mind the possibility of a rare monomorph epitheloid $A M L$ and if there is any doubt, it is crucial to exclude malignancy by using biopsy. A fat-poor AML can be a challenge to diagnose. It is vital to exclude malignancy, to take the size of the kidney AML in consideration, the high risk of potentially massive hemorrhage to decide on further management.

\section{Background}

The Bourneville Pringle disease, also called tuberous sclerosis complex (TSC) is a rare genetic disorder with dominant autosomal inheritance. ${ }^{1}$ The incidence of the disease is around 1:12 000, but this can vary in different countries. The name of the disease comes from a

French neurologist, Desire-Magloire-Bourneville, who described it first in 1880. Later on, Pringle supplemented the description of the syndrome with the cutaneous manifestations,

more precisely the facial angiofibromas, also called adenoma sebaceum. The hamartomatous neurocutan disorder was named after them. It is a rare neurocutaneous disorder, which can affect numerous internal organs, for example the kidney(s), the heart, and the lungs. The formation of multiple hamartomas is causing the multiorgan systemic involvement.

The tuberous sclerosis is caused by the mutation of the TSC1 (also called hamartin) and / or the mutation of TSC2 (also called tuberin) genes. ${ }^{2}$

The diagnostic criteria for the Bourneville Pringle disease were revised in 2012. To diagnose the tuberous sclerosis complex, 2 major criteria or 1 major and 2 minor criteria should be present. ${ }^{3}$ The major criteria 
include hypomelanotic macules ( $\geq 3$ of $\geq 5 \mathrm{~mm}$ in diameter), angiofibromas ( $\geq 3$ ) or fibrous cephalic plaque, ungula fibromas $(\geq 2)$, Shagreen patch, multiple retinal hamartomas, cortical dysplasias, subependymal nodules, subependymal giant cell astrocytomas, cardiac rhabdomyomas, lymphangioleiomyomatosis (LAM), angiomyolipomas $(\geq 2)$. The minor features include 'confetti' skin lesions, dental enamel pits $(>3)$, intraoral fibromas $(\geq 2)$, retinal achromic patch, multiple renal cysts, nonrenal hamartomas.

The formation of hamartomas in different organs cause the symptoms, and are responsible for manifestations of certain clinical features. ${ }^{4}$

Skin manifestations mainly include the formation of facial angiofibromas (adenoma sebaceum), periungual angiofibromas, fibrous cephalic plaques, shagreen patches and focal hypopigmentations. ${ }^{56}$

The neurological manifestations include epilepsy, formation of subependymal giant cell astrocytomas, TSC-associated neuropsychiatric disorders, intellectual disability, autism spectrum disorder. ${ }^{8}$

The pulmonary manifestation is caused by lymphangioleiomyomatosis (LAM) that most commonly cause dyspnea and, less commonly, cough, chest pain, and hemoptysis.

Among the kidney manifestations the angiomyolipomas and cysts appear more frequently, but rare cases of renal cell carcinomas, epitheloid monomorph angiomyolipoma and oncocytoma were also described. ${ }^{878}$

If the heart is affected, we can find cardiac rhabdomyomas.

\section{Case Presentation}

We present the case of a 43-year-old female affected by tuberous sclerosis complex, Bourneville Pringle disease, who was diagnosed at the age of 29.

The clinical manifestations started with skin symptoms. She firstly developed facial angiofibromas, adenoma sebaceum at a young age. Later, attended the dermatology department with periungual fibromas and with the appearance of hypopigmental patches on

the back. (Fig.1)

In her adolescent years the patient had epileptic episodes, in remission under the treatment of Pregabalin.In 2006, the abdominal ultrasonography revealed bilaterally enlarged kidneys with masses different in size and echogenicity, and a hypo echogenic mass on the upper pole of the left kidney and also an enlarged liver with 2 hyper echogenic, inhomogeneous masses.

An abdominal CT scan was requested, which described the above-mentioned renal lesions as possible bilateral angiolipomas. The hypo echogenic mass with a different solid aspect on the upper pole of the 
left kidney was described as a fat-poor CT scan component AML and the

malignancy could not be excluded either. The liver lesions were considered as hepatic angiolipomas.

(Fig. 2)

In order to prove or exclude malignancy, a CT guided biopsy was performed, which was reviewed by 2 pathologists. The histological findings showed an atypical renal angiomyolipoma, a rare monomorph, epitheloid type, which is known as a benign lesion, but certain patterns are potentially malignant, that need further observation. To determine these

patterns' potential to become malignant, the histological findings are essential.

The brain computer tomography (CT scan) and the brain magnetic resonance imaging (MRI) revealed typical lesions of tuberous sclerosis.

The patient was referred to the ophthalmology department; a hamartoma was found during the funduscopic evaluation.

A genetic examination was performed from the patient's specimen, which showed a mutation of the TSC2 c.2062 del, p. (Leu 688 Cysfs 10).

The lung manifestation, the lymphangioleiomyomatosis was diagnosed at the beginning of year 2020, starting with cough and dyspnea.

In the guidelines it is mentioned that in the case of a kidney $A M L$, a lesion $>4 \mathrm{~cm}$ or aneurysms $>5 \mathrm{~mm}$ in diameter, there is a high risk of potentially massive hemorrhage. ${ }^{9}$

Despite the histological findings and immunohistochemical features which were referring to a benign form of EM-AML, following the guidelines, taking the size of the lesions in consideration and the high risk to a potentially massive hemorrhage, the possibility of the surgery was offered. The patient refused to undergo urological surgery and decided to have interventions only for her skin manifestations.

The patient is being observed for 14 years now. The international guidelines recommend assessing renal function and blood pressure at least annually and renal imaging every 1-3 years. In our case, she developed secondary hypertension, which is treated with beta-blocker,

Metoprolol (Betaloc) 50mg 2x1 and valsartan plus hydrochlorothiazide (Co-Valsacor) 80/12,5 mg 2x1/2 with favorable outcome. The results of the last renal function test (2020.08.18) were between the normal intervals: creatinine $76 \mathrm{U} / \mathrm{L}$, carbamide $4,4 \mathrm{mmol} / \mathrm{L}$, eGFR $>60 \mathrm{ml} / \mathrm{min} / 1.73 \mathrm{~m} 2$. Concerning the renal imaging, MRI and CT scans were used, at the beginning every 6 months, then annually. The results of the renal imaging during the follow-up period, did not show significant progression. Her epilepsy is treated effectively with Pregabalin (Lyrica) 2x75 mg. 
After a 14 year follow up the patient is stable, under remission, without any progression regarding the renal lesions, without any renal surgical intervention.

Since the diagnosis of the lung manifestation (LAM) at the beginning of the year 2020, our patient is waiting for the approval to begin the mTOR inhibitor, Everolimus therapy.

\section{Discussion}

The tuberous sclerosis is a genetic disorder, which variably affects the neurological system, skin and among other internal organs, the kidneys, lungs, heart. The clinical manifestations are due to the multiorgan systemic involvement.

The kidney manifestation in most of the cases are cysts and angiomyolipomas. The AML is a benign tumor, which is composed by adipose tissue, blood vessels and smooth muscle cells. The classic $\mathrm{AML}$ is characterized by a high fat tissue component. In the literature, in some rare cases renal cell carcinoma, oncocytoma and a rare monomorph epitheloid AML can be present. ${ }^{10}$

The fat poor AML is a challenge to diagnose by computer tomography. In most of the cases the malignancy cannot be excluded either. A CT guided biopsy and the histological findings can help to diagnose and to decide further management and follow-up. Immunohistochemical

studies, detecting melanin A and HMB-45, diagnostic markers for AML, can differentiate the rare, monomorph, epitheloid type from RCC. ${ }^{11}$

In an epitheloid AML the epitheloid cells are predominant. In the literature there are no exact data concerning the required amount of epitheloid cells to differentiate a classic AML from an epitheloid AML. Aydin et al. investigated clinicopathologic features of 194 renal AML cases, highlighting the epitheloid component and they set a minimum proportion of $10 \%$ to define $A M L$ as an epitheloid AML. ${ }^{12}$

The renal angiomyolipomas are frequent clinical manifestations of TSC, which need careful surveillance to prevent life-threatening complications. In carefully selected patients conservative selective embolization, ablative therapies and mTOR inhibitor therapies and surgeries are the options.

Yamakado et al. reported that there was a strong correlation between the AML size and the aneurysm size and the risk of hemorrhage. ${ }^{13}$

In our case, taking into consideration the renal $A M L$ size and the recommendations of the guidelines (a lesion $>4 \mathrm{~cm}$ or aneurysms $>5 \mathrm{~mm}$ in diameter, with a high risk of a massive hemorrhage) a radical nephrectomy was offered, but the patient refused any surgical intervention. The anatomy of the lesion excluded the possibility of a conservative selective embolization. The patient is waiting for the approval for the mTOR inhibitor, Everolimus therapy. 


\section{Conclusions}

The Bourneville Pringle disease is a rare genetic, neurocutaneous disease, which can affect multiple organs by the formation of hamartomas, including renal manifestation as AML.

In case of radiological findings of a fat poor CT component AML it is essential to keep in mind the possibility of a rare monomorph epitheloid $A M L$ and if there is any doubt, it is crucial to exclude malignancy by using biopsy. A fat-poor AML can be a challenge to diagnose.

It is vital to exclude malignancy, to take in consideration the size of the kidney $A M L$, the high risk of potentially massive hemorrhage to decide on further management.

\section{Abbreviations}

TSC: Tuberous Sclerosis Complex

AML: angiomyolipoma

EM-AML: epitheloid monomorf angiomyolipoma

CT: computer tomography

mTOR inhibitor: mammalian target of rapamycin inhibitor

LAM: lymphangioleiomyomatosis

MRI: magnetic resonance imaging

RCC: renal cell carcinoma

\section{Declarations}

Conflict of interests: None

\section{Ethics approval and consent to participate}

Our case report was approved by our institutional ethics committee, with the following reference number 22/2021. Consent of the patient signed, uploaded.

\section{Consent for publication}

Consent of the patient signed, uploaded.

\section{Availability of data and material}

Data will not be shared, because of private informatical healthcare system of the hospital. 


\section{Competing interests}

The author declares that the research was conducted in the absence of any commercial or financial relationships that could be construed as a potential conflict of interest.

\section{Funding}

Not applicable

\section{Authors' contributions}

MK has coordinated the study. Follow-up of the patient was coordinated by BI. MF, MK has analyzed the patient's previous history. MK, MF, ZT and VL drafted, proofread and edited the manuscript. All authors read and approved the final manuscript.

\section{Acknowledgements}

We thank to Dr. Becker Krisztina for the photos of the patient's dermatological manifestations and for our radiologists, Dr. Markó Róbert and Dr. Volford Gábor for their cooperation. And we also thank to Dr.Buzogány István for the excellent technical support and to Dr. Vrecenár László language editor for proofreading the manuscript.

\section{References}

1. Alshaiji JM, Spock CR, Connelly EA, Schachner LA. Facial angiofibromas in a mosaic pattern tuberous sclerosis: A case report. Dermatol Online J 2012;18:8.

2. Rodrigues DA, Gomes CM, Costa IM. Tuberous sclerosis complex. An Bras Dermatol 2012;87:184-96.

3. Roach ES, Gomez MR, Northrup H. Tuberous sclerosis complex consensus conference: Revised clinical diagnostic criteria. J Child Neurol 1998;13:624-8.

4. Kwiatkowski DJ. Tuberous sclerosis: From tubers to mTOR. Ann Hum Genet 2003;67(Pt 1):87-96.

5. Webb DW, Clarke A, Fryer A, Osborne JP. The cutaneous features of tuberous sclerosis: A population study. Br J Dermatol 1996;135:1-5.

6. Sahar El Aoud et al. Tuberous Sclerosis Complex (Bourneville-Pringle Disease) in a 25-year- old Female with Bilateral Renal Angiomyolipoma and Secondary Hypertension, Saudi J Kidney Dis Transpl 2017;28(3):633-638

7. Rosser T, Panigrahy A, McClintock W. The diverse clinical manifestations of tuberous sclerosis complex: A review. Semin Pediatr Neurol 2006;13:27-36.

8. Ben Hamida F, Gorsane I, Gharbi C, et al. Renal manifestations in tuberous sclerosis. Rev Med Interne 2006;27:836-42

9. Anil Kapoor et al. Evolving Strategies in the Treatment of Tuberous Sclerosis Complex-associated Angiomyolipomas (TSC-AML) Urology 2016 Mar;89:19-26. doi: 10.1016/j.urology.2015.12.009. Epub 
2015 Dec 23.

10. Henske, E. P., Jóźwiak, S., Kingswood, J. C., Sampson, J. R., \& Thiele, E. A. 2016). Tuberous sclerosis complex. Nature Reviews Disease Primers, 2, doi:10.1038/nrdp.2016.35

11. John C. Hulbert, and John J. Bissler, Tuberous Sclerosis Complex Renal Disease, Nephron Exp Nephrol. 2010Bradley P. Dixon Nov; 118(1): e15-e20.

12. Aydin H, Magi-Galluzzi C, Lane BR, Sercia L, Lopez JI, Rini BI, Zhou M. Renal angiomyolipoma: clinicopathologic study of 194 cases with emphasis on the epithelioid histology and tuberous sclerosis association. Am J Surg Pathol. 2009 Feb;33(2):289-97. doi: 10.1097/PAS.0b013e31817ed7a6. PMID: 18852677.

13. Yamakado K, Tanaka N, Nakagawa T, Kobayashi S, Yanagawa M, Takeda K. Renal angiomyolipoma: relationships between tumor size, aneurysm formation, and rupture. Radiology. 2002;225:78-82.

\section{Figures}

\section{Figure 1:}

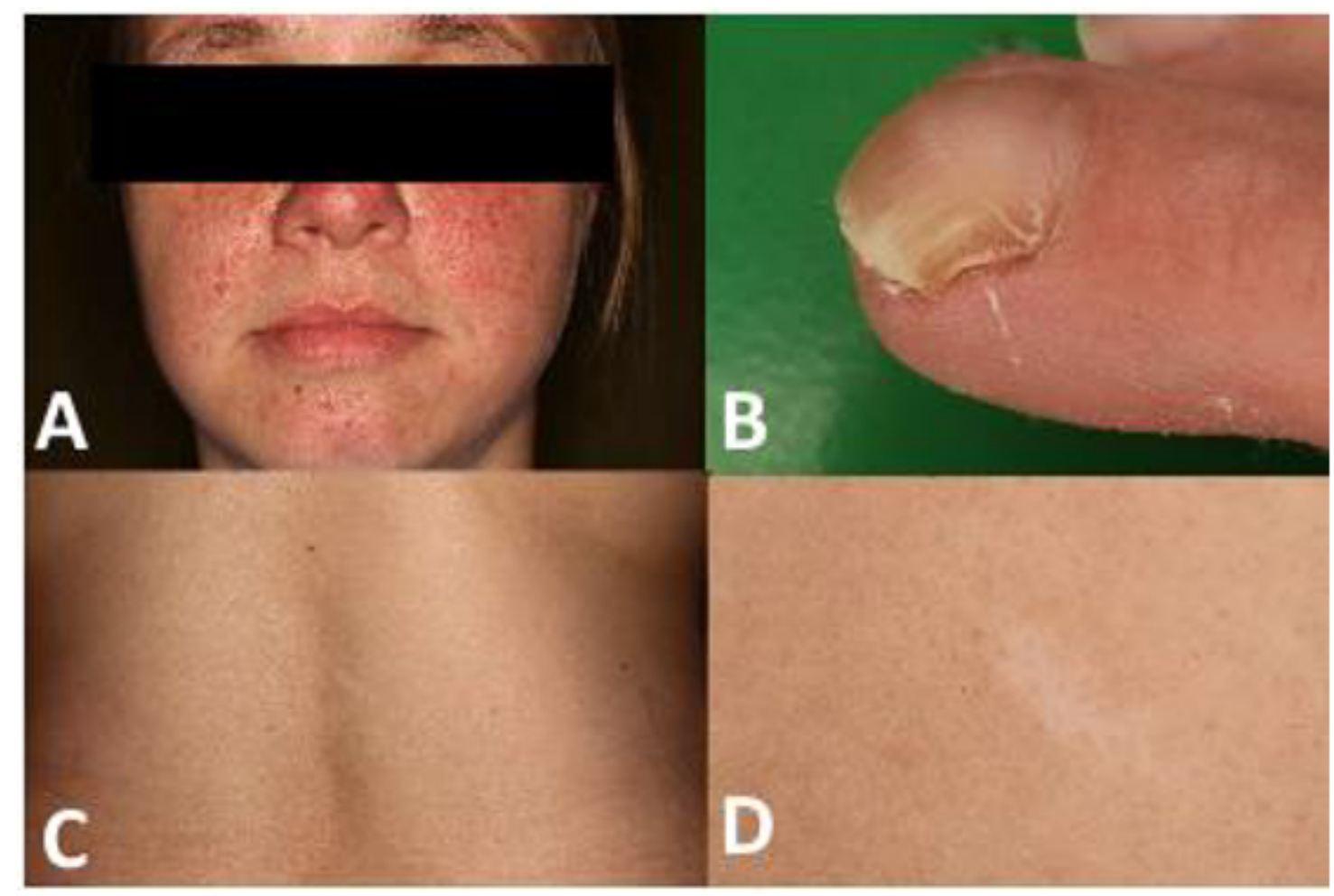

Figure 1: A:Facial angiofibromas, B:periungual fibromas, C,D: hypopigmental patches Department of Dermatology, Semmelweis, Budapest (dr. Becker Krisztina's photos)

\section{Figure 1}

See image above for figure legend 
Figure 2:

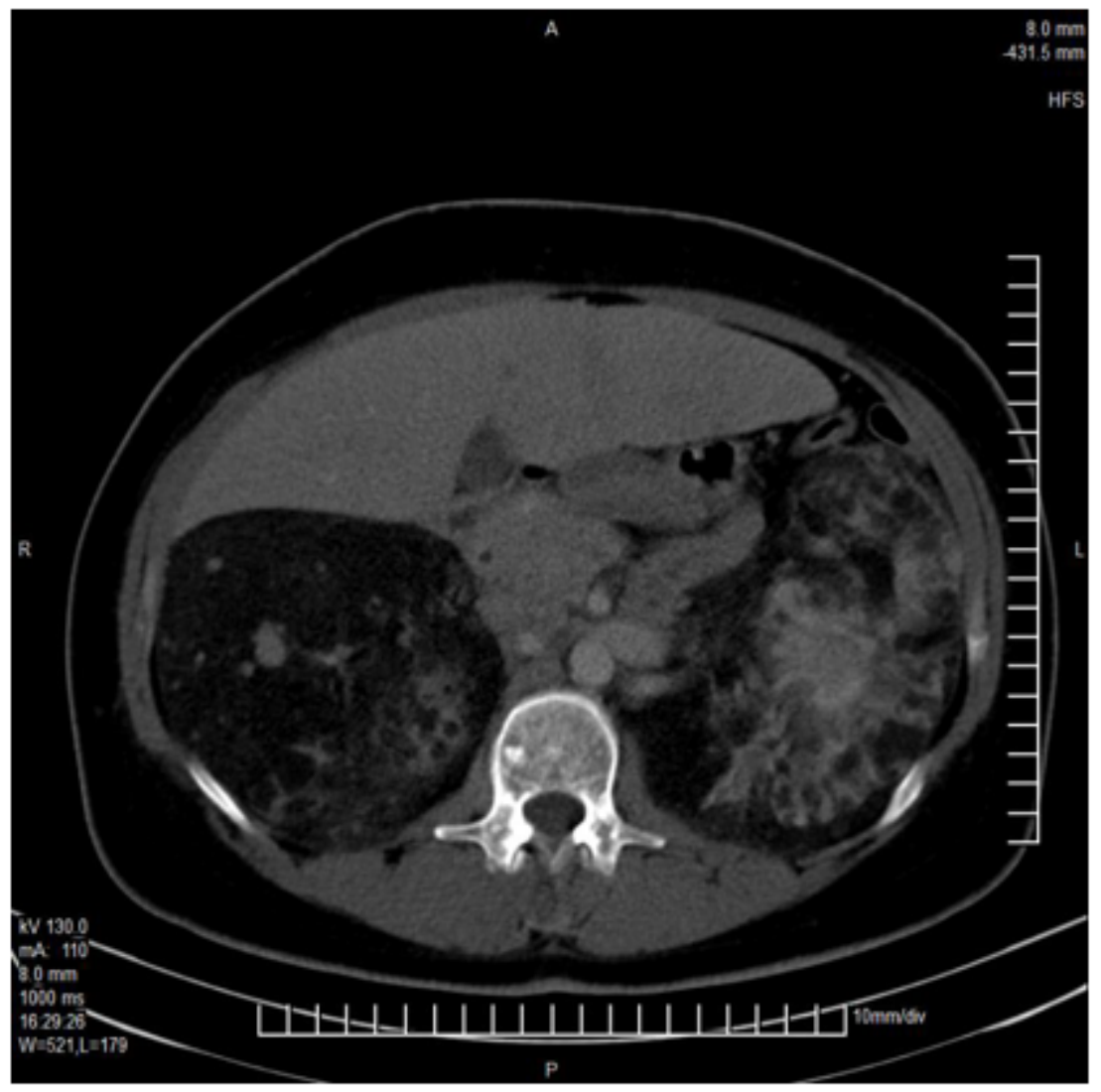

Figure 2: Bilateral renal angiomyolipoma

\section{Figure 2}

See image above for figure legend 